\title{
The Effect of Physical Activity and Gender on Well Being and Body Image of Adolescents
}

\author{
Eleftheria Petrakaki' ${ }^{1}$, Eirini Karakasidou ${ }^{2}$ \\ ${ }^{1}$ Institution of Counselling and Psychological Studies, I.C.P.S., Athens, Greece \\ ${ }^{2}$ University of Central Lancashire, Preston, UK \\ Email: e.petrakaki@hotmail.com
}

How to cite this paper: Petrakaki, E., \& Karakasidou, E. (2017). The Effect of Physical Activity and Gender on Well Being and Body Image of Adolescents. Psychology, 8, 1840-1856.

https://doi.org/10.4236/psych.2017.811120

Received: July 29, 2017

Accepted: September 18, 2017

Published: September 21, 2017

Copyright ( 92017 by authors and Scientific Research Publishing Inc. This work is licensed under the Creative Commons Attribution International License (CC BY 4.0).

http://creativecommons.org/licenses/by/4.0/

\section{(c) (i) Open Access}

\begin{abstract}
The aim of the current study is to investigate the interaction between gender and physical activity with the three variables (subjective happiness, self-esteem and body image). More specifically, we will test if there is a difference between the variables (subjective happiness, self-esteem and body image) and if any gender differences are present. Method: A hundred and eleven (111) adolescent students ( 58 girls, 53 boys) who ranged in age from 13 to 17 years participated in the study. Because the participants were adolescents, their parents first completed the inform consent for their child's participation. Then the students completed demographic factors in order to allocate them in exercisers or no-exercisers and sexual orientation and the three questionnaires. A 2 (exercisers, non-exercisers) $\times 2$ (male, female) $\times 3$ (Self Esteem Scale, Subjective Happiness Scale, Social Physique Anxiety Scale) multivariate ANOVA was conducted. Results: The statistical analysis revealed a significant correlation between the three variables (Self Esteem Scale, Subjective Happiness Scale and Social Physique Anxiety Scale). Furthermore, it revealed a significant main effect of exercisers on Self Esteem Scale, Subjective Happiness Scale and Social Physique Anxiety Scale but not significant effect of gender on the three variables, as well as a non-significant interaction of group and gender on the three variables. Conclusion: These findings are both in consistency with previous literature that exercise has mental prosperities in adolescents, but also in non-consistency as gender is concerned. As a result, future studies could be conducted in order to investigate further the impact of physical activity and gender in self-esteem, subjective happiness and social physique anxiety.
\end{abstract}

\section{Keywords}

Physical Activity, Gender, Well Being, Body Image, Adolescents 


\section{Introduction}

Over the previous year's obesity is accounted for to be a developing wellbeing issue everywhere throughout the world (Swinburn et al., 2011 as cited in Hoor et al., 2015). Longitudinal studies demonstrate an immediate relationship with cardiovascular illnesses (Jousilahti et al., 1996; Attard et al., 2013). It has additionally been demonstrated that weight pick up, as a danger element for other sickness advancement, is a trademark of grown-ups as well as of youngsters and youths (Kapantais, 2010). It is accounted for to be one of the real hazard variables of constant metabolic and cardiovascular ailments (Hoor et al. 2015). In overweight and obese kids and young people (5 - 17-year olds), metabolic wellbeing, as well as mental prosperity is accounted for, to be at danger (Hoor et al. 2015). Moderate power activity of a non-organized nature appears to encourage a large portion of disease prevention and health promoting benefits. With new rules advancing a not so extreme but rather more time customer way to deal with consistent physical action, it is trusted that an upward pattern in the physical movement designs, and extraordinarily kids at danger for chronic disease, will create sooner rather than later (Sothern et al., 1999). More reasons exist; not withstanding genetic lack of protection and excess eating as reported insufficient level of physical activity is one of the essential givers to youthfulness overweight and weight (Hoor et al., 2015). Physical activity is described as any significant advancement conveyed by skeletal muscles that results in imperativeness use (Caspersen, Powell, \& Christensen, 1985; Cavill, Biddle, \& Sallis, 2001). General support in physical activity (PA) is basic for good wellbeing. Dynamic individuals advantage from more elevated amounts of wellbeing related wellness and are at lower danger of creating various debilitating medicinal conditions than dormant individuals (Eime et al., 2013). Customary interest in physical activity (PA) is vital for good wellbeing in youngsters and teenagers (6 - 9 years old). Be that as it may, in spite of the significance of PA, an expansive extent of kids is not getting adequate levels of day by day physical activity (Loprinzi et al., 2012). It is generally recognized that the medical advantages of interest in PA are not restricted to physical wellbeing but rather additionally join mental parts (Eime et al., 2013). According to the review of Bailey (2006) which investigates scientific evidence on the commitments and advantages of physical education and sport (PES), reveals reinforcement in a plethora of areas, such as physical, lifestyle, affective, social and cognitive. The review proposes that PES can make foremost and unmistakable commitments to the improvement in each of these zones, similar to the advancement of social abilities and social practices, self-regard and pro-school states of mind, and, in specific circumstances, scholastic and psychological improvement (Bailey, 2006). This perception is in accordance with the recent study of Samek et al. (2015) where the findings propose that secondary school sports inclusion might be an outstanding variable identified with persistent antisocial behavior beginning starting in youth and pre-adulthood and enduring through youthful adulthood. According to the literature, physical activity 
is both physical and mentally gainful for youngsters. One of the factors that will be explored is the association of physical activity with higher levels of self-esteem. Physical activity and work out have been connected to mental prosperity; more particularly brings down tension, makes positive inclination and positive self-perceptions and additionally improve self-esteem. Investment in game and physical action might be especially urgent for the improvement of mental prosperity in kids and young people (Slater \& Tiggemann, 2011). Generally, the studies report moderate confirmation that physical action is mentally useful for youth. In Calfas and Taylor's (1994) survey, self-esteem and self-concept have been concentrated on as critical indicators of numerous sorts of human conduct, extending from scholarly execution to solitary exercises, and these variables may intervene other mental states. The most predictable impact was for self-regard/self-idea and tension/stress variables (Calfas \& Taylor, 1994). Besides, physical activity can add to enhancements in self-concept and self-esteem. Truth be told, self-concept has been depicted as the variable with the most astounding result in physical activity and identity research (Calfas \& Taylor, 1994).

The first factor under investigation is self-esteem. Literature suggests that physical activity in teenagers has enhancements in self-esteem and self-concept, depressive indications and tension (Calfas \& Taylor, 1994). A person's self-concept is accepted to be comprised of psychological, behavioral and assess parts. Self-esteem alludes to the third of these, and is characterized as the "level of worldwide respect one has for the self" (Harter, 1993: p. 87 as cited in Frost \& McKelvie, 2004). The recurrence of consideration in sports frequently has been at the same time and longitudinally associated with higher self-esteem. The comprehension of this alliance dependably has been encompassed as consideration in diversions inciting bigger measures of self-esteem after some time, although no studies have attempted whether more raised measures of self-esteem lead to extended relationship in sports as time goes on (Adachi \& Willoughby, 2013). Furthermore, in some studies, gender differences have been reported on self-esteem with male participants having higher scores. According to Frost \& McKelvie's (2004) study, it is reported a positive correlation on body satisfaction with self-esteem. The sexual orientation contrast in self-esteem, and the relationship between self-esteem and cathexis, may create as early as in primary school (Frost \& McKelvie, 2004). Fredrickson and Roberts (1997) suggested, support that physical activity during adolescents may help young ladies oppose self-objectification and its negative outcomes. Moreover, Frost \& McKelvie (2004) hypothesized that self-esteem of girls and ladies might be lower in the older than in the adolescent students and that boy's and men's self-esteem might be higher in the older students than in more youthful. Then again, there might be a drop in self-esteem for the secondary school girls and an expansion for the secondary school boys. Frankly, both male and female optional school understudies scored lower than school students or undergrads. That is, there was a drop for both secondary school girls and boys (Frost \& McKelvie, 2004). On the 
contrary, Wade (1991) reported that no gender differences are identified in older adolescents in self-esteem. Additionally, Fredrickson \& Roberts (1997), report that adolescence is an especially disturbing entry for young ladies. In fact, sexual orientation contrasts in the greater part of the psychological wellness dangers, first develop during adolescence. Certainly, most adolescents, male or female, experience drops in self-esteem (Fredrickson \& Roberts, 1997).

Another factor that is reported to have a positive effect is subjective happiness. In the study of Valois et al. (2004) it is accounted for that countless open secondary school students are reporting disappointment with their lives, and that a liberal number of open secondary school youths are not sharing in physical movement practices. Above all, this study showed a vital linkage between two unmistakable fiery success research unique works: the prosperity danger conduct composing and the individual satisfaction (life fulfillment) forming. This study perceived colossal relationship between self-reported life fulfillment and non-commitment in physical activity practices. Additionally, the study showed the significance of two material segments as center individuals of the relationship between life fulfillment and particular sorts of physical activity practices. The nature and size of the nonattendance of physical activity conduct and life fulfillment affiliations were basically influenced by both sexual orientation and ethnicity (Valois et al., 2004).

A third variable that is under investigation is the social physique anxiety in regard of physical activity. Taking an interest in secondary school physical education (PE) can be a distressing knowledge for a few teenagers (Carlson, 1995). Alongside worries as for nonappearance of wellness to participate and/or participate in the different games and physical activities offered in the PE classes (Carlson, 1995), there is a confluence of social and formative components that can build understudies' anxiety about performing and/or showing their bodies before others (Cox, Ullrich-French, \& Sabiston, 2013). Barriers to organized and leisure PA may vary amongst boys and girls. Girls might probably report problems like, humiliation, sweating, apprehension of harm, and weight feedback by associates and relative contrasted with young men (Loprinzi et al., 2012). Furthermore, Slater \& Tiggermann (2011) found a positive connection of teasing in the game setting and body-image concerns toward both young men and young ladies. Boys and girls who reported more encounters of teasing while playing sport and other physical movement additionally reported larger amounts of self-objectification and body-image concerns (Slater \& Tiggermann, 2011). In the study of Cox et al. (2013) it was investigated how social physique anxiety (SPA) consolidated with various examples of inspiration directions may encourage versus prevent exertion and happiness in physical education (PE) and recreation time physical activity. The outcomes demonstrated higher sentiments of SPA in PE seem connected with lower levels of happiness and exertion in PE and relaxation time physical movement outside of school just when combined with higher outer direction. This discovering clarifies conflicting relationship 
amongst SPA and physical activity results (Cox, Ullrich-French, \& Sabiston, 2013). Furthermore, Koukourikos in his diploma thesis in Aristotelio University in Thessaloniki, investigated dietary attitudes and behaviours of young people which aimed in the detection investigation of differences in physical activity, eating behavior and eating attitudes among young men and women. The results indicated that high levels of physical stress can lead young people to unhealthy eating behaviors. Moreover there is a differentiation in physical exercise between men and women. Finally, women are strongly oriented to an ideal image of their body, but they do not prefer to exercise as a way to obtain the desired body. Therefore they resort to the control diet, which leads them more easily than men in abnormal eating behaviors (Koukourikos, 2010-2011). These may result in a strictly self-weighting routine which is connected with various undesirable practices and poorer mental prosperity (Quick et al., 2013). In particular, discoveries show that young people who oftentimes self-measure themselves are at expanded danger for various risky wellbeing practices and poorer mental results. For overweight young people, successive self-weighing was also connected with various constructive results. Based upon these discoveries, any proposals for weight observing ought to be made carefully; all youths, including overweight young people, ought to be prompted not to take part in incessant self-measuring practices. Moreover, any teenagers taking part in continuous self-measuring practices ought to be checked for dangerous results (Quick et al., 2013). Moreover, the type of exercise can affect body image with Slater \& Tiggermann's (2011) study to support that girls exercising at a gym having larger amounts of body shame and confused symptomatology than the individuals who did not practice at a gym. Self-ruling inspiration and need fulfillment decidedly anticipated activity upkeep in both sexes. Nonetheless, contrasts between sexual orientations were seen in the extra commitment made by body image and weight related variables. In girls, the most imperative of these was the level of pressure perceived from others to get more fit, and extra change was represented by body weight for stature higher perceived pressure and BMI were connected with drop out from activity, while low scores were emphatically connected with its uptake. For boys, body fulfillment was decidedly connected with the support of activity investment (Gillison et al., 2011). Additionally, Frost \& McKelvie (2004) could not reveal age and gender difference in the measures of body satisfaction.

As reported, another important factor in the positive effects of physical activity is the frequency that is been done. Cavill et al. (2001) scheduled an intervention to energize sufficient physical activity for all youngsters, starting at a youthful age, and with a particular spotlight on the inactive. They suggested that a normal of 1 hour of physical activity every day is the favored proposal. At any rate twice per week, some of these exercises ought to assistance to upgrade and keep up solid quality and adaptability, and bone wellbeing. Numerous youngsters have been appeared to have no less than one modifiable coronary illness hazard variable; and numerous youngsters have side effects of mental misery. Hence, it 
was closed the suggestion ought to stimulate increased physical movement among youngsters (Cavill et al., 2001). Consequently it was included the examination the frequency of support in a physical activity. It was picked the recurrence of commitment in amusements rather than asking youngsters how long each week they play sports since adolescents may be less disposed to recall decisively the aggregate number of hours consistently that they play sports. Case in point, various youngsters play a couple of particular amusements amid the same time frame and their preoccupations and practices as often as possible vary in term, as needs be making it difficult to audit the precise number of hours consistently that they play sports. Subsequently, the stays that were utilized may prompt less mistake fluctuation in youngsters' self-reports of their recurrence of consideration in any physical action, diverged from reporting the exact hours consistently (Adachi \& Willoughby, 2013). It is though noteworthy to mention that according to Merglen's et al. (2014) study, relationship was found between weekly sport practice and adolescent well-being. Youths in the low and high participation groups indicated more than a twofold risk of reporting poor well-being compared to those practicing 7 hours for every week which is suggested. This association between the duration of the activity and prosperity demonstrated a dose-reaction design. The top scores of well-being were around 14 hours for every week of game practice, which compares to double the recommender participation of 7 hours. Nevertheless, the well-being was opposite when rehearsing for more than 17.5 hours for each week (Merglen et al., 2014).

The current study aims to investigate the interaction between gender and physical activity with the three variables (subjective happiness, self-esteem and body image). More specific, we will test if there is there is a difference between the variables (subjective happiness, self-esteem and body image) and if there any gender differences are present. As observed, little to no literature exists on subjective happiness in global level, as well as more specific in Greek adolescent population.

According to the literature on the topic the research hypotheses that we examined were:

1) That exercisers will have greater scores in self-esteem, subjective happiness and body image than non-exercisers;

2) Explore gender differences between self-esteem, subjective happiness and body image;

3) The relationship among self-esteem, subjective happiness and body image.

\section{Method}

\subsection{Design}

A 2 (gender: male, female) $\times 2$ (group: exercise, not exercise) $\times 3$ (Questionnaires: self-esteem scale, subjective happiness, social physique anxiety scale) multivariate ANOVA was used in order to conduct the study and a correlation across the variables. The gender (male, female) and group (exercisers, non-exercisers) were 
defined as between subjects factor, whereas the questionnaires [self-esteem scale (ses), subjective happiness (sh) and social physique anxiety (spas)] as within subjects factor.

\subsection{Participants}

The participants were hundred and eleven (111) adolescents ( 58 girls, 53 boys) who ranged in age from 13 to 17 years $(M=14.58, S D=1.85)$. The students were volunteers from Gerakas Arts High School and Gerakas 3rd High School. The participants completed all measures at school in the presence of the researcher and the researcher. As is often the case with surveys, height and weight were self-reported. The students reported a mean height of $\mathrm{M}=1.64, \mathrm{SD}=0.08$ and mean weight of $53 \mathrm{~kg}(M=53.83, S D=10.10)$. Furthermore, 52 did exercise and 59 of the adolescents did not exercise.

\subsection{Materials}

The materials used in order to conduct this study were the measure of subjective happiness (Lyubomirsky \& Lepper, 1999), the Rosenberg's Self Esteem Questionnaire (SES) (Rosenberg, 1965) and the Social Physique Anxiety Scale (SPAS) (Hart, Leary, \& Rejeski, 1989).

The participants were informed about the study and were asked to complete some demographic questions related to their age, gender, weight and height (in order to measure BMI (body mass image) if needed). Participants were posed a question about current participation in game and other physical exercises or not. If they partook in some type of physical activity, students were gotten some information about their present cooperation status in any composed game or work out (e.g. basketball, tennis, swimming). Additionally, they were asked to report the frequency from their support in physical activity $(0-2$ times per week, $3+$ times per week).

\subsubsection{Self-Esteem}

Rosenberg Self-Esteem Scale (Rosenberg, 1965) as used in its Greek version, translated and validated by Galanou, Galanakis, Alexopoulos, \& Darviri (2014). A 10-item scale that measures worldwide self-esteem by measuring both positive and negative sentiments about the self. The scale is accepted to be uni-dimensional. All things are addressed utilizing a 4-point Likert scale ranging from strongly agree to strongly disagree. Reliability: The RSE shows a Guttman scale coefficient of reproducibility of 0.92 , demonstrating incredible internal consistency. Test-retest eliability quality over a time of 2 weeks uncovers connections of 0.85 and 0.88 , showing amazing solidness. Validity: Demonstrates simultaneous, prescient and build validity utilizing known groups. The RSE correlates essentially with different measures of self-esteem, including the Coopersmith Self-Esteem Inventory. Also, the RSE correlates in the anticipated direction with measures of depression and anxiety (Rosenberg, 1979). 


\subsubsection{Subjective Happiness}

Subjective Happiness Scale (SHS) was used, which is a 4-item scale of worldwide subjective happiness. Two items request that respondents portray themselves utilizing both supreme appraisals and evaluations in respect to peers, while the other two things offer brief portrayals of happy and unhappy people and ask respondents the degree to which every portrayal depicts them. The SHS has been approved in 14 studies with a total of 2732 members. Results have demonstrated that the SHS has high internal consistency, which has been observed to be steady crosswise over examples. The alpha's range from 0.79 to $0.94(\mathrm{M}=0.86)$. Test-retest and self-peer correlations have proposed great to brilliant reliability with 0.55 to $0.90(\mathrm{~m}=0.72)$, and construct validation investigations of focalized and discriminant validity, 0.52 to $0.72(\mathrm{M}=0.62)$ have affirmed the use of this scale to measure the construct of subjective happiness (Lyubomirsky \& Lepper, 1999).

\subsubsection{Social Physique Anxiety}

Social Physique Anxiety Scale (SPAS) was used, which measures social anxiety identified with physique. By body or figure we mean your body's form and structure; particularly, muscle to fat ratio ratios, solid tone, and general body extents. The Social Physique Anxiety Scale (SPAS) showed both high internal and test-retest reliability. It additionally correlated appropriately with concerns in regards to others' assessments and with sentiments about one's body. Validity data demonstrated that ladies who scored high on the SPAS were heavier and had a higher rate of muscle to fat ratio ratios than the individuals who scored lower. Additionally, high scorers reported altogether more noteworthy anxiety during a real assessment of their physiques, further supporting the validity of the scale (Hart, Leary, \& Rejeski, 1989; Psychountaki, Stavrou, \& Zervas, 2004).

\subsection{Procedure}

Ethical approval for the study was obtained from the University of Central Lancashire and Institution of Counseling and Psychological Studies.

The sample was students from High Schools in Athens, consequently an authorization from the director of secondary education was ensured. Out of 6 contacted schools 2 schools agreed to participate. Participants were adolescents, therefore an inform consent was distributed to all students for their parents to sign. Participants were firstly be welcomed and provided with a verbal and written brief and project information. They were also informed that if they felt any discomfort they would withdraw at any time. The experimenter after distributed the questionnaires counterbalanced in order to control for any false responses, due to fatigue or outside factor. All participants completed Self-esteem scale, subjective happiness and social physique anxiety scale No personal information was completed by the participants besides age, gender weight and height [in order to measure body mass index (BMI) if needed] for the study. After the completion of the questionnaires, participants received a verbal debriefing and were 
thanked for their participation and were asked if any question they might have had were answered. The questionnaires were collected and placed in a folder that were sealed and were only opened by the researcher. They were then codified with numbers in order to produce an ID for each participant's questionnaire.

\section{Results}

For this research the data that were used for this analysis were the gender of the students, the group of Participation (exercisers, non-exercisers) across the three variables (Self Esteem Scale-SES, Subjective happiness-SH and social physique anxiety-SPAS). In Table 1, the means and standard deviations are presented.

Before conducting the MANOVA, a progression of Pearson relationships were performed between the majority of the depentent variables keeping in mind the end goal to test the MANOVA supposition that the needy variables would be connected with each other in the moderate reach (Meyers, Gampst, \& Guarino, 2006). As can be found in Table 2, an important example of relationships was seen amongst the majority of the needy variables, proposing the suitability of a MANOVA. Also, the Box's M estimation of 24,45 was connected with a $p=$ 0.124 , which was deciphered as non-significant (i.e., $p<0.005$ ) Therefore, the covariance networks between the groups were thought to be equal for the reasons for the MANOVA.

Table 1. Means and SDs of gender and group for self-esteem, subjective happiness and social physique anxiety.

\begin{tabular}{|c|c|c|c|c|c|c|}
\hline \multirow{3}{*}{ Students } & \multicolumn{6}{|c|}{ Questionnaires Used } \\
\hline & \multicolumn{2}{|c|}{ SES } & \multicolumn{2}{|c|}{ SHS } & \multicolumn{2}{|c|}{ SPAS } \\
\hline & M & SD & M & SD & M & SD \\
\hline \multicolumn{7}{|l|}{ Gender } \\
\hline Male & 29.0 & 3.55 & 17.37 & 3.23 & 34.71 & 4.50 \\
\hline $\mathrm{n}=53$ & & & & & & \\
\hline Female & 29.9 & 3.84 & 18.12 & 2.57 & 34.70 & 4.90 \\
\hline $\mathrm{n}=58$ & & & & & & \\
\hline \multicolumn{7}{|l|}{ Group } \\
\hline Exercisers & 31.0 & 3.66 & 18.75 & 3.24 & 33.10 & 4.26 \\
\hline $\mathrm{n}=52$ & & & & & & \\
\hline Non-exercisers & 28.1 & 3.22 & 16.90 & 2.29 & 36.02 & 4.03 \\
\hline $\mathrm{n}=59$ & & & & & & \\
\hline
\end{tabular}

Table 2. Correlation between variables.

\begin{tabular}{cccc}
\hline & SES & SHS & SPAS \\
\hline SES & 1.0 & & \\
SHS & $0.35^{*}$ & 1.0 & \\
SPAS & $-0.25^{*}$ & $-0.20^{*}$ & 1.0 \\
\hline
\end{tabular}


All variables were significantly correlated. Self-esteem and Subjective happiness were significantly correlated, $r=0.05, p<0.001$. Self-esteem and social physique anxiety were significantly negative correlated, $r=-0.25, p=0.007$. Subjective happiness and social physique anxiety were significantly negative correlated, $r=-0.20, p=0.03$.

A non-significant Box's M test $(p=0.12)$ indicates homogeneity of covariance matrices of the dependent variables with gender and group. The homogeneity of variance assumption was not violated as it was indicated from the Levene's Test that was non-significant in SES $p=0.06$, in SH $p=0.11$ and in SPAS $p=0.97$.

As seen in Table 3 , the multivariate effect was non-significant by gender, Wilks' $\lambda=0.987, F(3,105)=0.45, p=0.72, \quad \eta_{p}^{2}=0.013$. A significant multivariate effect was revealed for group of exercise on the combined dependent variables, Wilks' $\lambda=0.757, F(3,105)=11.22, p<0.001, \eta_{p}^{2}=0.24$. Furthermore, There was a non-significant interaction between gender $\mathrm{x}$ group on the combined dependent variables, Wilks' $\lambda=0.994, \mathrm{~F}(3,105)=0.21, p=0.89, \eta_{p}^{2}=$ 0.0 .

In order to determine the significance of these differences a series of univariate ANOVAs are conducted and indicated a significant effect of group across SES, $F(1,107)=18.74, p<0.001, \eta_{p}^{2}=0.15$, SH, $F(1,107)=11.31, p=0.001$, $\eta_{p}^{2}=0.10$ and SPAS, $F(1,107)=13.83, p<0.001, \eta_{p}^{2}=0.11$. Examination of the marginal means indicates that exercise group $(\mathrm{M}=31.08, S E=0.49)$ performed better in SES than non-exercise group $(\mathrm{M}=28.19, S E=0.45)$ as seen in Figure 1.

Moreover, Exercise group also performed better in Subjective happiness scale $(\mathrm{M}=18.73, \mathrm{SE}=0.39)$ than non-exercisers $(\mathrm{M}=16.93, \mathrm{SE}=0.36)$ as seen in Figure 2 .

Table 3. Multivariate tests.

\begin{tabular}{ccccccc}
\hline & Wilks $\lambda^{\prime}$ & $\mathrm{F}$ & $\mathrm{df1}$ & $\mathrm{df2}$ & $\mathrm{p}$ & $\eta_{p}^{2}$ \\
\hline Gender & 0.987 & 0.45 & 3 & 105 & 0.72 & 0.013 \\
Group & 0.757 & 11.22 & 3 & 105 & $<0.001$ & 0.013 \\
Gender $\times$ Group & 0.994 & 0.21 & 3 & 105 & 0.89 & 0.01 \\
\hline
\end{tabular}

\section{SES}

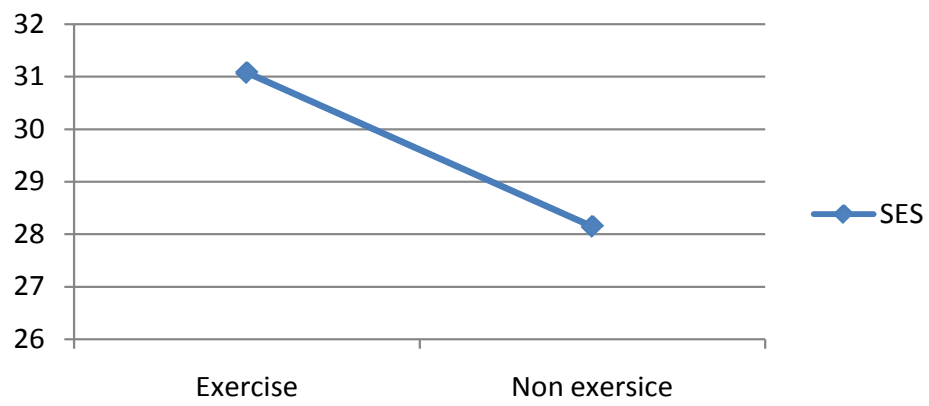

Figure 1. Estimated marginal means of Ses on group. 
However, in SPAS non-exercisers performed better $(\mathrm{M}=36.02, \mathrm{SE}=0.54)$ than exercisers $(\mathrm{M}=33.03, S E=0.59)$ as seen in Figure 3.

\section{Discussion}

The aim of the present study was to investigate the interaction between gender and physical activity with the three variables (self-esteem, subjective happiness and social physique anxiety) as well as the relationship across variables. Hypothesis that group of exercisers will have greater scores on self-esteem scale, subjective happiness and lower scores of social physique anxiety than the group of non-exercisers was confirmed. The hypothesis that gender differences will be present across the three variables was not confirmed. Furthermore, the results did not present any interaction of gender and exercisers or non-exercisers. Moreover, the results revealed a relationship among self-esteem, subjective happiness and social physique anxiety.

Physical activity revealed an association with self-esteem, subjective happiness and social physique anxiety. More specific, the results of the present study support the findings of previous studies, that physical activity promotes self-esteem (Calfas \& Taylor, 1994; Frost \& McKelvie, 2004). Furthermore, physical activity was found to promote subjective happiness, which is in accordance with Valois et al. (2004), which found associations between perceived happiness with physical activity. The lower the physical activity of the student, the lower the perceived

\section{SH}

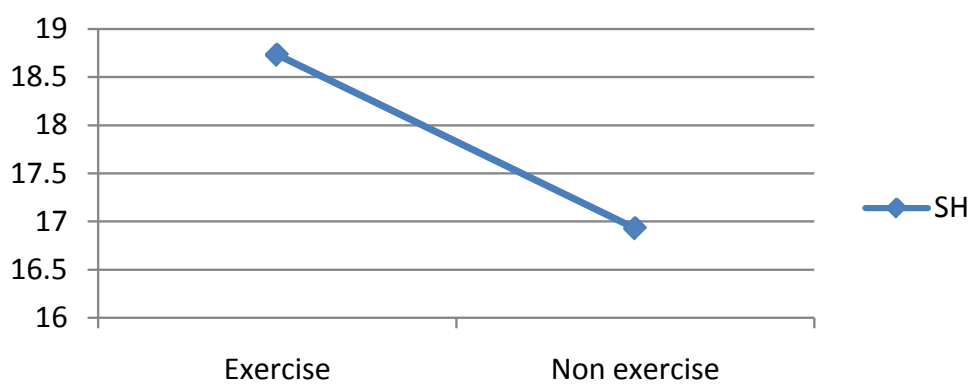

Figure 2. Estimated marginal means of subjective happiness on group.

SPAS

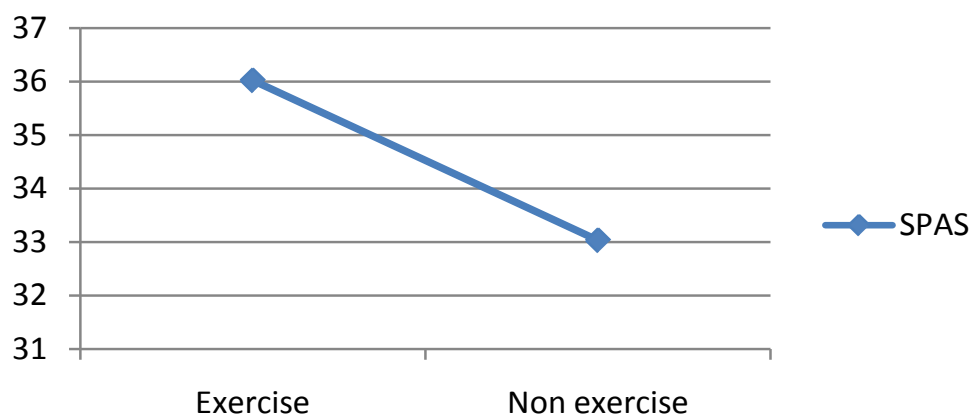

Figure 3. Estimated marginal means of SPAS in group. 
happiness and the higher the negative emotions. Literature is limited as far as subjective happiness is concerned. More specifically, no other study in Greece investigating the interaction of physical activity with subjective happiness in adolescents was found. Third factor that was found an interaction was Social physique anxiety, where the result proposes that as the levels of exercise and physical activity of the student increase, social physique anxiety of the student drops. This finding in accordance with Cox, Ullrich-French \& Sabiston (2013) where they found that higher feelings of social physique anxiety in physical education appear linked with lower levels of enjoyment and effort in physical education.

As mentioned earlier, the results did not support gender differences any of self-esteem, subjective happiness and social physique anxiety variables. These results are in contrary with previous studies (Frost \& McKelvie, 2004; Gillison et al. 2011; Loprinzi et al., 2012) who support gender differences, with boys having greater self-esteem than girls and that girls might be more concerned about their physical appearance during physical activity. Other studies though, support that gender difference exists (Wade, 1991; Slater \& Tiggermann, 2011). For example, in Frost \& McKelvie's (2004) study was found gender difference on self-esteem, but could not reveal any gender difference in the measures of body satisfaction. Therefore, the literature does not seem to support or not gender differences across variables. On the contrary, in Valois et al. (2004) it was reported that the nature and greatness of the absence of PA conduct and life fulfillment affiliations were essentially impacted by both sexual orientation and ethnicity, without concluding in gender differences, rather than influence of gender on the type of exercise and the attitudes revealed by that. Both male and female participating in some form of physical activity, seem to hold greater levels of perceived happiness. One, possible explanation of the non significance of the results, is that it might be influenced also by age. According to Frost \& McKelvie (2004) self-esteem of girl and women may be lower in the older than in the youth students and that boy's and men's self-esteem may be higher in the older students than in younger. On the other hand, it was estimated a drop in self-esteem for the secondary school girls and an increase for secondary school boys. Results demonstrated that both male and female secondary school students scored lower than evaluation school students or undergrads. That is, there was a drop for both secondary school girls and boys (Frost \& McKelvie, 2004).

Regarding to the interaction of gender and group on self-esteem, subjective happiness and social physique anxiety the results indicated no interaction between them. These results are in contrast with Snyder \& Spreitzer (1976) study on female athletes and non-athletes. Their results indicate that athletes had higher self-perceptions of athletic ability than the non-athletes. The athletes' perceptions of their body image were generally more positive than the non-athletes. Studies report gender differences on self-esteem with male participants having higher scores. Furthermore, Fredrickson and Roberts (1997) suggested, participation in physical activity during adolescence may help girls resist 
self-objectification. But these are separate studies that report benefits of participation in physical activity or not according to gender, but no interaction of these two across self-esteem, subjective happiness or social physique anxiety. Therefore, the results are not clear.

Regarding study limitations, the use of self-report questionnaires, especially in adolescents might be one. Even though the validity and the reliability of self-esteem scale, subjective happiness scale and social physique anxiety scale are present, the fact that they were addressed in adolescents might have been occurred biases. Self-report measures are often inclined to biases by the participants, especially for the measure of psychological constructs (Howell, 2013). In order to minimize the bias, anonymity and confidentiality were assured; therefore participants could express themselves more liberal.

One other limitation of the study, is the number of participants was limited and from a specific area (Gerakas, Athens, Attica district). Perhaps a further investigation in a sample of students throughout Attica district, or even better throughout Greece conclude in better results. There might be present differences in rural areas of Greece in opposition to towns, on the participation in physical activity or not. Furthermore, a greater sample of students might have revealed a gender difference on self-esteem, subjective happiness or social physique anxiety.

It would be interesting to investigate if age is a determinant in participation in physical activity, as well as in the levels self-esteem, subjective happiness and body image. According to Frost \& McKelvie (2004) self-esteem of girl and women may be lower in the older than in the youth students and that boy's and men's self-esteem may be higher in the older students than in younger. It would be interesting to investigate if such variations exist in Greek adolescents.

Another interesting factor for future investigation might be the type of exercise, and which contributes greater in each variable. According to Slater \& Tiggermann's (2011) study the type of exercise can affect body image, with girls exercising at a gym having larger amounts of body shame and confused symptomatology than the individuals who did not practice at a gym.

Furthermore, the investigation of body mass index (BMI) could contribute in the results of participation in sport. Literature suggests that contrasts between sexual orientations were seen in the extra commitment made by body image and weight related variables. In girls, the most imperative of these was the level of pressure perceived from others to get more fit, and extra change was represented by body weight for stature higher perceived pressure and BMI were connected with drop out from activity, while low scores were emphatically connected with its uptake. For boys, body fulfillment was decidedly connected with the support of activity investment (Gillison et al. 2011). Therefore, qualitative differences exist between male and female participation in sport which would be interesting to explore.

Additionally, the major reason that children get involved in some kind of physical activity or sport is the amusement it gives to them. According to these findings, crucial advances of the association between inclusion in sports and 
self-esteem are present. Maybe if adolescents are encouraged by the guardians, educators and other required to find a amusement that they absolutely recognize at a youthful age, they may encounter increase in self-esteem, which, thusly, may set them on dynamic and solid headings that proceed into their adolescent and grown-up years.

Unmistakably, physical exercise can possibly make critical commitments to the training and improvement of kids and youngsters from numerous points of view, albeit further research and assessment will help us better comprehend the way of these commitments. All things considered, in each of the areas talked about there is confirmation that physical exercise can have a positive and significant impact. In some regards, such an impact is extraordinary, inferable from the unmistakable settings in which physical exercise happen. Thusly, there is an obligation for the individuals who instruct and recognize the estimation of physical exercise to go about as backers for its place as an essential component of the general training of all kids. A note of alert ought to be sounded, as well. The investigative confirmation does not bolster the case that these impacts will happen naturally. There is no motivation to trust that basically supporting interest in physical exercise will fundamentally achieve positive changes to youngsters or to their groups. The activities and connections of educators and mentors to a great extent figure out if or not kids and youngsters encounter these positive parts of physical exercise and regardless of whether they understand its extraordinary potential. Settings that underscore positive physical exercise encounters, described by delight, differing qualities, and the engagement of all, and that are overseen by submitted and prepared instructors and mentors, and steady and educated guardians, are fundamental.

\section{Conclusion}

In conclusion, physical activity has been proven to be basic for good wellbeing and mental prosperity (Eime et al., 2013; Loprinzi et al., 2012). Furthermore, according to the review of Bailey (2006) PES can possibly make noteworthy and unmistakable contributions to the enhancement in each of these areas, like the improvement of social aptitudes and social behaviours, self-esteem and pro-school mentalities, and, in specific circumstances, academic and cognitive advancement. The results indicated that participation in physical activity and sport increases self-esteem, subjective happiness and decreases social physique anxiety. Furthermore, gender did not appear to have an impact in these variables. Moreover, no interaction was found between gender and participation or not in some physical activity, across self-esteem, subjective happiness and social physique anxiety. The results are in accordance with previous literature supporting that physical activity promotes physical and mental well-being. Additionally, the result extends the literature by adding that participation in sport increases subjective happiness in adolescent population. As a result, future studies should be conducted in order to investigate further interactions of physical activity. 


\section{References}

Adachi, P. J., \& Willoughby, T. (2013). It's Not How Much You Play, but How Much You Enjoy the Game: The Longitudinal Associations between Adolescents' Self-Esteem and the Frequency Versus Enjoyment of Involvement in Sports. Journal of Youth and Adolescence, 43, 137-145. https://doi.org/10.1007/s10964-013-9988-3

Attard, S. M., Herring, A. H., Howard, A. G., \& Gordon-Larsen, P. (2013). Longitudinal Trajectories of BMI and Cardiovascular Disease Risk: The National Longitudinal Study of Adolescent Health. Obesity, 21, 2180-2188. https://doi.org/10.1002/oby.20569

Bailey, R. (2006). Physical Education and Sport in Schools: A Review of Benefits and Outcomes. Journal of School Health, 76, 397-401. https://doi.org/10.1111/j.1746-1561.2006.00132.x

Calfas, K. J., \& Taylor, W. C. (1994). Effects of Physical Activity on Psychological Variables in Adolescents. Pediatric Exercise Science, 6, 406-423.

https://doi.org/10.1123/pes.6.4.406

Carlson, T. B. (1995). We Hate Gym: Student Alienation from Physical Education. Journal of Teaching in Physical Education, 14, 467-477. https://doi.org/10.1123/jtpe.14.4.467

Caspersen, C. J., Powell, K. E., \& Christenson, G. M. (1985). Physical Activity, Exercise and Physical Fitness: Definitions and Distinctions for Health-Related Research. Public Health Reports, 100, 126-131.

Cavill, N., Biddle, S. J. H., \& Sallis, J. F. (2001) Health-Enhancing Physical Activity for Young People: Statement of the United Kingdom Expert Consensus Conference. Pediatric Exercise Science, 13, 12-25. https://doi.org/10.1123/pes.13.1.12

Cox, A. E., Ullrich-French, S., \& Sabiston, C. M. (2013). Using Motivation Regulations in a Person-Centered Approach to Examine the Link between Social Physique Anxiety in Physical Education and Physical Activity-Related Outcomes in Adolescents. Psychology of Sport and Exercise, 14, 461-467. https://doi.org/10.1016/j.psychsport.2013.01.005

Eime, R. M., Young, J. A., Harvey, J. T., Charity, M. J., \& Payne, W. R. (2013). A Systematic Review of the Psychological and Social Benefits of Participation in Sport for Children and Adolescents: Informing Development of a Conceptual Model of Health through Sport. International Journal of Behavioral Nutrition and Physical Activity, 10, 98. https://doi.org/10.1186/1479-5868-10-98

Fredrickson, B. L., \& Roberts, T. (1997). Objectification Theory: Towards Understanding Women's Lived Experiences and Mental Health Risks. Psychology of Women Quarterly, 21, 79-101. https://doi.org/10.1111/j.1471-6402.1997.tb00108.x

Frost, J., \& McKelvie, S. (2004). Self-Esteem and Body Satisfaction in Male and Female Elementary School, High School, and University Students. Sex Roles, 51, 45-54. https://doi.org/10.1023/B:SERS.0000032308.90104.c6

Galanou, C., Galanakis, M., Alexopoulos, E., \& Darviri, C. (2014). Rosenberg Self-Esteem Scale Greek Validation on Student Sample. Psychology PSYCH, 5, 819-827. https://doi.org/10.4236/psych.2014.58093

Gillison, F. B., Standage, M., \& Skevington, S. M. (2011). Motivation and Body-Related Factors as Discriminators of Change in Adolescents' Exercise Behavior Profiles. Journal of Adolescent Health, 48, 44-51. https://doi.org/10.1016/j.jadohealth.2010.05.006

Hart, E. A., Leary, M. R., \& Rejeski, W. J. (1989). The Measurement of Social Physique Anxiety. Journal of Sport and Exercise Psychology, 11, 94-104.

https://doi.org/10.1123/jsep.11.1.94 
Hoor, G. A., Plasqui, G., Ruiter, R. A., Kremers, S. P., Rutten, G. M., Schols, A. M., \& Kok, G. (2015). A New Direction in Psychology and Health: Resistance Exercise Training for Obese Children and Adolescents. Psychology \& Health, 31, 1-8. https://doi.org/10.1080/08870446.2015.1070158

Howell, D. (2013). Fundamental Statistics for the Behavioral Sciences. Boston: Cengage Learning.

Jousilahti, P., Tuomilehto, J., Vartiainen, E., Pekkanen, J., \& Puska, P. (1996). Body Weight, Cardiovascular Risk Factors, and Coronary Mortality: 15-Year Follow-Up of Middle-Aged Men and Women in Eastern Finland. Circulation, 93, 1372-1379.

https://doi.org/10.1161/01.CIR.93.7.1372

Kapantais, E., Chala, E., Kaklamanou, D., Lanaras, L., Kaklamanou, M., \& Tzotzas, T. (2010). Breakfast Skipping and Its Relation to BMI and Health-Compromising Behaviours among Greek Adolescents. Public Health Nutrition, 14, 101-108. https://doi.org/10.1017/S1368980010000765

Koukourikos, K. (2010-2011). Intrinsic Activity in Specific Populations. Unpublished Diploma Thesis.

Loprinzi, P. D., Cardinal, B. J., Loprinzi, K. L., \& Lee, H. (2012). Benefits and Environmental Determinants of Physical Activity in Children and Adolescents. Obesity Facts, 5, 597-610. https://doi.org/10.1159/000342684

Lyubomirsky, S., \& Lepper, H. S. (1999). A Measure of Subjective Happiness: Preliminary Reliability and Construct Validation. Social Indicators Research, 46, 137-155. https://doi.org/10.1023/A:1006824100041

Merglen, A., Flatz, A., Bélanger, R. E., Michaud, P. A., \& Suris, J. C. (2014). Weekly Sport Practice and Adolescent Well-Being. Archives of Disease in Childhood, 99, 208-210. https://doi.org/10.1136/archdischild-2013-303729

Meyers, L. S., Gamst, G., \& Guarino, A. J. (2006). Applied Multivariate Research: Design and Interpretation. London: Sage.

Psychountaki, M., Stavrou, A. N., \& Zervas, I. (2004). Social Physique Anxiety Scale: Adaption in Greek Population. In Y. Theodorakis (Ed.), Proceedings of the 8th National -3rd International Congress of Sport Psychology (pp. 28-30). Trikala.

Quick, V., Loth, K., Maclehose, R., Linde, J. A., \& Neumark-Sztainer, D. (2013). Prevalence of Adolescents' Self-Weighing Behaviors and Associations with Weight-Related Behaviors and Psychological Well-Being. Journal of Adolescent Health, 52, 738-744. https://doi.org/10.1016/j.jadohealth.2012.11.016

Rosenberg, M. (1965). Rosenberg Self-Esteem Scale (RSE). Acceptance and Commitment Therapy. Measures Package, 61, 52.

Rosenberg, M. (1979). Conceiving the Self. New York: Basic Books.

Samek, D. R., Elkins, I. J., Keyes, M. A., Iacono, W. G., \& McGue, M. (2015). High School Sports Involvement Diminishes the Association between Childhood Conduct Disorder and Adult Antisocial Behavior. Journal of Adolescent Health, 57, 107-112.

https://doi.org/10.1016/j.jadohealth.2015.03.009

Slater, A., \& Tiggemann, M. (2011). Gender Differences in Adolescent Sport Participation, Teasing, Self-Objectification and Body Image Concerns. Journal of Adolescence, 34, 455-463. https://doi.org/10.1016/j.adolescence.2010.06.007

Snyder, E. E., \& Spreitzer, E. (1976). Correlates of Sport Participation among Adolescent Girls. Research Quarterly. American Alliance for Health, Physical Education and Recreation, 47, 804-809. 
Sothern, M. S., Loftin, M., Suskind, R. M., Udall, J. N., \& Blecker, U. (1999). The Health Benefits of Physical Activity in Children and Adolescents: Implications for Chronic Disease Prevention. European Journal of Pediatrics, 158, 271-274.

https://doi.org/10.1007/s004310051070

Valois, R. F., Zullig, K. J., Huebner, E. S., \& Drane, J. W. (2004). Physical Activity Behaviors and Perceived Life Satisfaction among Public High School Adolescents. Journal of School Health, 74, 59-65. https://doi.org/10.1111/j.1746-1561.2004.tb04201.x

Wade, T. J. (1991). Race and Sex Differences in Adolescent Self-Perceptions of Physical Attractiveness and Level of Self-Esteem during Early and Late Adolescence. Personality and Individual Differences, 12, 1319-1324.

https://doi.org/10.1016/0191-8869(91)90207-R

\section{Scientific Research Publishing}

Submit or recommend next manuscript to SCIRP and we will provide best service for you:

Accepting pre-submission inquiries through Email, Facebook, LinkedIn, Twitter, etc. A wide selection of journals (inclusive of 9 subjects, more than 200 journals)

Providing 24-hour high-quality service

User-friendly online submission system

Fair and swift peer-review system

Efficient typesetting and proofreading procedure

Display of the result of downloads and visits, as well as the number of cited articles

Maximum dissemination of your research work

Submit your manuscript at: http://papersubmission.scirp.org/

Or contact psych@scirp.org 